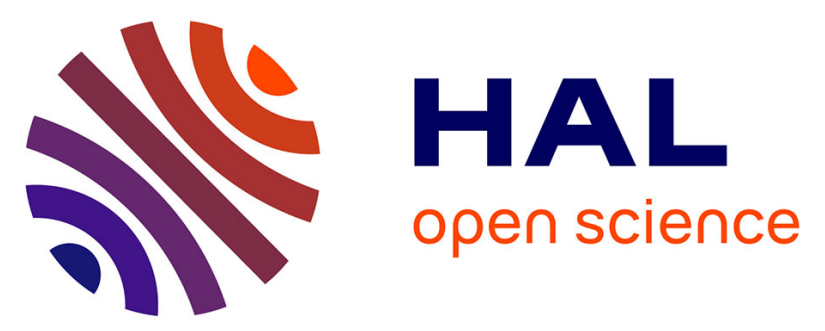

\title{
Increases in heart rate and systolic blood pressure in anaesthetized dogs affected with X-linked muscular dystrophy after cisatracurium administration: a retrospective study.
}

\author{
Francesco Staffieri, Maria Paula Larenza, Margaret M Sleeper
}

\section{To cite this version:}

Francesco Staffieri, Maria Paula Larenza, Margaret M Sleeper. Increases in heart rate and systolic blood pressure in anaesthetized dogs affected with X-linked muscular dystrophy after cisatracurium administration: a retrospective study.. Pediatric Anesthesia, 2011, 21 (8), pp.900. 10.1111/j.14609592.2011.03579.x . hal-00630282

\section{HAL Id: hal-00630282 https://hal.science/hal-00630282}

Submitted on 8 Oct 2011

HAL is a multi-disciplinary open access archive for the deposit and dissemination of scientific research documents, whether they are published or not. The documents may come from teaching and research institutions in France or abroad, or from public or private research centers.
L'archive ouverte pluridisciplinaire HAL, est destinée au dépôt et à la diffusion de documents scientifiques de niveau recherche, publiés ou non, émanant des établissements d'enseignement et de recherche français ou étrangers, des laboratoires publics ou privés. 


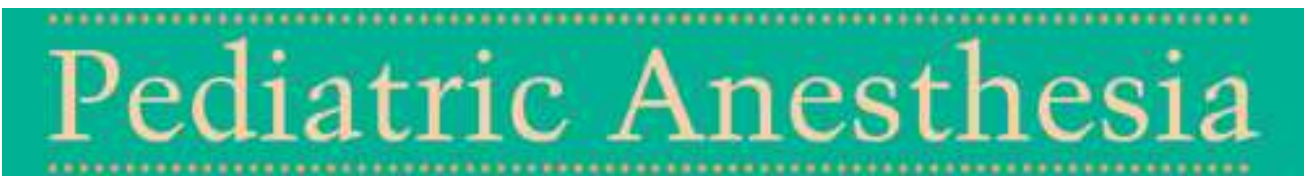

\section{Increases in heart rate and systolic blood pressure in anaesthetized dogs affected with X-linked muscular dystrophy after cisatracurium administration: a retrospective study.}

\begin{tabular}{|r|l|}
\hline Journal: & Pediatric Anesthesia \\
\hline Manuscript ID: & PAN-2010-0447.R2 \\
\hline Wiley - Manuscript type: & Original Paper \\
\hline Author: & 19-Feb-2011 \\
\hline Komplete List of Authors: & $\begin{array}{l}\text { Staffieri, Francesco; University of Bari, D.E.T.O., Sez. di Chirurgia } \\
\text { Veterinaria } \\
\text { Larenza, Maria Paula; Matthew J. Ryan Veterinary Hospital, School } \\
\text { of Veterinary Medicine, University of Pennsylvania, Department of } \\
\text { CLinical Studies } \\
\text { Sleeper, Margaret M; Matthew J. Ryan Veterinary Hospital, School } \\
\text { of Veterinary Medicine, University of Pennsylvania, Department of } \\
\text { CLinical Studies }\end{array}$ \\
\hline Key & $\begin{array}{l}\text { Duchennes muscular dystrophy < Muscle disorders, neuromuscular } \\
\text { blocking drugs < Drugs, Research }\end{array}$ \\
\hline
\end{tabular}

\section{SCHOLARONE \\ Manuscripts}


The enclosed manuscript has been read and approved by all authors, it is not under active consideration for publication elsewhere, has not been accepted for publication, nor has been published in full or in part (except in abstract form).

Valenzano, 25/09/2010

Dr Francesco Staffieri

Dipartimento dell'Emergenza e dei Trapianti d'Organo, Sezione di Chirurgia

Veterinaria, Università degli Studi di Bari, Italy

Prof Sleeper Margaret

Matthew J. Ryan Veterinary Hospital, School of Veterinary Medicine,

University of Pennsylvania, PA, USA

Prof Larenza Paula M

Matthew J. Ryan Veterinary Hospital, School of Veterinary Medicine, University of Pennsylvania, PA, USA 


\section{Pediatric Anesthesia}

\section{Author Checklist for Submission to Pediatric Anesthesia}

\section{FOR ALL PEDIATRIC ANESTHESIA PAPERS}

\section{PUBLICATION POLICY}

$\exists \mathrm{I} /$ We confirm that this submission has not been previously published, will not be offered simultaneously elsewhere, that all authors have read and approved the content, that authors have declared all competing interests, that the work complies with the Ethical Policies of the Journal, and the work has been conducted under internationally accepted ethical standards after relevant ethical review.

曰 I/We confirm that a completed Copyright Transfer Agreement (www.wiley.com/go/ctaaglobal), has been uploaded onto ScholarOne Manuscripts as a supporting document.

\section{ETHICS}

$\boxminus$ Manuscripts describing studies involving animals should comply with local/national guidelines governing the use of experimental animals and must contain a statement indicating that the procedures have been approved by the appropriate regulatory body. Manuscripts concerned with human studies must contain statements indicating that informed, written consent has been obtained, that studies have been performed according to the Declaration of Helsinki (www.wma.net/e/policy/b3.htm) and that the procedures have been approved by a local ethics committee. If individuals might be identified from a publication (e.g. from images or from details), authors must obtain explicit consent from the individual.

\section{DISCLOSURES}

$\boxminus \quad \mathrm{I}$ We confirm that all authors have disclosed any financial interests in any company or institution that might benefit from their publication and have provided details of any other potential competing interests of a personal nature that that might be considered relevant to their publication.

$\boxminus \quad$ I/We confirm also that all authors fulfil the following three criteria:

- Substantial contributions to research design, or the acquisition, analysis or interpretation of data

- Drafting the paper and/or revising it critically

- Approval of the submitted and final versions.

$\boxminus$ I confirm that all authors have submitted the Conflict of Interests Form uploaded onto ScholarOne Manuscripts as a supporting document. 


\section{CLINICAL TRIALS (IF APPLICABLE)}

I confirm that if my paper reports a clinical trial, it adhere to the tenets of the CONSORT statement (JAMA 2001; 285: 1987-1991). A flow chart is provided describing the progress of patients through the trial. A checklist of CONSORT requirements has also been completed.

\section{LANGUAGE}

$\boxminus \quad \mathrm{I} /$ We confirm that in my/our opinion the quality of written English in this paper is of sufficiently high standard to enable review of the article.

Please note authors of manuscripts with a poor standard of English will be directed towards our English Language Editing Service (http://authorservices.wiley.com/bauthor/english language.asp).

$\boxminus \mathrm{I} /$ We confirm that I/we have read the Instructions to authors and have followed the journal style for language, units, etc.

\section{FORMAT/SUBMISSION}

$\Xi \quad \mathrm{I} /$ We confirm that the structure of the paper and its format adheres to the guidelines in the Instructions to Authors (www.wiley.com/bw/submit.asp?ref=1350-1925\&site=1).

$\boxminus \quad$ I/We confirm that figures were prepared according the Instructions to Authors and that the size and resolution are sufficient for publication and that they are uploaded as TIF or EPS files. For details, please see the guidelines: http://authorservices.wiley.com//bauthor/Authorguidefiles/BEA0602c.pdf.

\section{SUBMISSION LENGTH AND FIGURES}

$\boxminus \quad \mathrm{I} /$ We confirm that the length of my submission is no more than

$\boxminus \quad 2,500$ words, 6 tables or figures and 25 references (for Original articles)

3,000 words, 6 table or figure and 5 references and 35 references (for Review articles)

800 words, 1 table or figure and 5 references (for Letters)

1000 words, 1 table or figure and 5 references (for Case reports).

I have included supplementary figures of tables (please state how many)

These word limits exclude acknowledgements and disclosures, references, tables, figure and table legends and figures. Manuscripts that do not meet these formal criteria will be returned for reformatting, which will delay submission.

$\boxminus$ Exceptions to these guidelines may be made in certain circumstances, at the discretion of the Editors. If you require an exemption, please indicate this in your cover letter.

Colour figures can be included as necessary, but the author is responsible for covering the costs. 


\section{COLOUR WORK AGREEMENT}

It is Journal policy to charge authors for all colour reproduction (except for invited review articles and online-only papers) in the Journal. If you wish to reproduce your figures in colour, you must complete and return a Colour Work Agreement (CWA) form before your paper can be published.

$\square \quad$ I/We confirm that I/we have submitted a completed CWA

(www.blackwellpublishing.com/pdf/SN Sub2000 P CoW.pdf), uploaded onto ScholarOne Manuscripts as a supporting document.

For any questions about completing this form, please contact the Editorial Office at paneditorialoffice@gmail.com. 
Increases in heart rate and systolic blood pressure in anaesthetized dogs affected with X-linked muscular dystrophy after cisatracurium administration: a retrospective study.

F. Staffieri ${ }^{\circ}$, M. Sleeper ${ }^{\circ}$, M.P.Larenza ${ }^{\circ}$

${ }^{\circ}$ Matthew J. Ryan Veterinary Hospital, School of Veterinary Medicine, University of Pennsylvania, PA, USA.

*Dipartimento dell'Emergenza e dei Trapianti d'Organo, Sezione di Chirurgia Veterinaria, Università degli Studi di Bari, Italy.

Corresponding author:

Dr F. Staffieri: Dipartimento dell'Emergenza e dei Trapianti d'Organo, Sezione di Chirurgia Veterinaria, Università degli Studi di Bari, SP per Casamassima km 3 70010, Valenzano, Bari, Italy

f.staffieri@veterinaria.uniba.it

Running title: cisatracurium in X-linked muscular dystrophy 


\begin{abstract}
Background: Most patients affected with Duchenne muscular dystrophy (DMD) present with arrhythmias and cardiomyopathies. Drugs which potentially may induce tachycardia or hypertension could precipitate acute cardiac failure in these patients and should be avoided.
\end{abstract}

Methods: Thirty anesthesia records of 5 experimental male golden retriever cross-bred dogs affected with X-linked muscular dystrophy (GRDM) a model of DMD, were retrospectively reviewed (DMD group). Anesthesia records were compared with those of 10 golden retriever dogs not affected with muscular dystrophy (control group). Records were excluded if dogs received anticholinergics or vasoactive amines. Anesthesia was induced with fentanyl followed by propofol, both intravenously. After orotracheal intubation all dogs' lungs were mechanically ventilated. Anesthesia was maintained with and infusion of fentanyl and propofol (DMD group) or isoflurane in oxygen (control group). Pure $\mathrm{O}_{2}$ was provided to the DMD group. Cisatracurium $\left(0.1 \mathrm{mg} \mathrm{kg}^{-1}\right)$ was administered intravenously to all dogs. Fivemin interval recordings of HR and SAP were obtained.

Results: Immediately after the administration of cisatracurium, absolute values for $\mathrm{HR}$ and SAP significantly increased by $78.3 \pm 37.0$ beats minute $^{-1}(115.4 \pm 64.9 \%)$ and $33.0 \pm 28.3$ $\mathrm{mmHg}(33.5 \pm 31.2 \%)$, respectively, in all DMD dogs, and remained significantly increased for 10 and 30 minutes, respectively. Dogs in the control group did not show significant increases of HR or SAP after cisatracurium administration. All dogs recovered from anesthesia without complications.

Conclusion: In this report, increases in HR and SAP could be associated with the administration of cisatracurium in individuals affected with X-linked muscular dystrophy. These cardiovascular changes deserve further investigation. 
Keywords: X-linked muscular dystrophy, dogs, cisatracurium, heart rate

1

4

5

6

7

8

9

10

11

12

13

14

15

16

17

18

19

20

21

22

23

24

25

26

27

28

29

30

31

32

34

35

36

37

38

39

40

41

42

43

44

45

46

47

48

49

50

51

52

53

54

55

56

57

58

59 


\section{Introduction}

Duchenne's muscular dystrophy (DMD) is an X-linked disease caused by mutations in the dystrophin gene, resulting in disintegration of the dystrophin glycoprotein complex, instability of the muscle cell membrane and uncontrolled influx of calcium (1). The progressive nature of the disease results in restrictive pulmonary function, multiple contractures, scoliosis and cardiomyopathy. Respiratory insufficiency and cardiomyopathy are predominant factors contributing to early morbidity and mortality (2).

Several animal models for DMD have been investigated in order to test new treatments that improve the quality of life and possibly cure the disorder (3). Among these animal models the golden retriever X-linked muscular dystrophy (GRMD) has been regarded as one of the best suited mammalian models for preclinical therapy and for specific experimental therapeutic approaches such as the use of stem cells or the testing of viral vectors (3). The myocardial involvement is much more evident in GRMD dogs than in other animal models, matching very closely the cardiac complications encountered in DMD patients (4).

It has been recognized that patients with DMD have an increased risk for complications when they undergo general anesthesia (5). In particular the use of the depolarizing muscle relaxant succinylcholine has been absolutely contraindicated because its administration is associated with life-threatening hyperkalemia (6). As cardiac autonomic function is usually altered in patients with DMD, the use of non-depolarizing neuromuscular blockers (NDNMB) with vagolytic actions (i.e. gallamine, pancuronium) should also be avoided as they may induce tachycardia and precipitate cardiac failure. Atracurium, an intermediate-acting benzylisoquinolinium NDNMB, has been suggested as a good alternative for these patients as it lacks vagolytic actions and undergoes Hofmann's degradation (7). However, research and/or clinical data are missing to support this recommendation. 


\section{Materials and Methods}

DMD group

The anesthesia records $(n=30)$ of 5 purpose bred, experimental male golden retriever crossbred dogs affected with X-linked muscular dystrophy, weighting between 16.3 and $22.5 \mathrm{~kg}$, that underwent general anesthesia for the execution of magnetic resonance imaging (MRI) studies of the heart and hind limbs were retrospectively reviewed. Each dog was anesthetized once a month in the period of time between January 2009 and June 2009 as part of a larger study in which the benefits of gene therapy were investigated. Each dog was investigated before and after the beginning of the gene therapy. Gene therapy was performed between the first and second anesthetic episodes and has been described elsewhere (8) Briefly, the therapy consists of transferring a gene vector, a self complementary adeno-associated virus, with the dogs under general anesthesia and using a percutaneous transendocardial injection catheter under fluoroscopy guidance.

The study had been approved by the University of Pennsylvania Animal Care and Use Committee. Dogs were raised under National Institutes of Health and US department of Agriculture guidelines for the care and use of animals in research. Dogs were fasted for 8 hours (with free access to water) prior to any anesthetic episode. Dogs did not show clinical signs of cardiomyopathy at the time of the scans. 
After catheterization of a cephalic vein, general anesthesia was induced in all dogs with an intravenous (IV) administration of $0.010-0.012 \mathrm{mg} \mathrm{kg}^{-1}$ of fentanyl (Fentanyl Citrate USP, Hospira, Lake Forest, IL, USA) followed by $3-4 \mathrm{mg} \mathrm{kg}^{-1}$ of propofol (PropoFlo, Abbott, Chicago IL, USA). The dog's trachea was intubated with a cuffed silicone tube which was connected to a small animal anesthesia machine via a circle system that was used for oxygen delivery $\left(50-100 \mathrm{ml} \mathrm{kg}^{-1}\right.$ minute $\left.^{-1}\right)$. General anesthesia was maintained with a constant rate infusion (CRI) of propofol $\left(0.1-0.2 \mathrm{mg} \mathrm{kg}^{-1}\right.$ minute $\left.^{-1}\right)$ using a roller pump (Vet-Pro VIP 2000, Caesarea Medical Electronics, Liechtenstein, Germany) and fentanyl $\left(0.5-0.7 \mu \mathrm{g} \mathrm{kg}^{-1}\right.$ minute $^{-1}$ ) administered through a second IV catheter placed in the contralateral cephalic vein using a syringe pump (Graseby syringe pump 3400, Smith Medical MD, St. Paul MN, USA) and titrated to maintain an adequate level of anesthesia (absence of jaw tone and palpebral reflex and ventro-medial rotation of the ocular globe). The constant rate infusions were connected to the catheter via a small extension " $T$ " set that had an independent injection port to allow for the intravenous administration of additional drugs without altering the infusion rates of fentanyl or propofol (Microbore extension set with "T" and prepierced injection site, Hospira, Lake Foprest IL, USA). All dogs' lungs were mechanically ventilated using a pneumatically driven ventilator with preset volume and flow rate (Nuffield Anaesthesia Ventilator Series 200, Penlon, Abingdon, Oxon, UK). The ventilator was set to deliver a flow rate of $0.25 \mathrm{~mL} \mathrm{sec}^{-1}$ with an inspiratory to expiratory ratio (I:E) between $1: 3$ and $1: 3.5$ to achieve a peak inspiratory pressure of $10-15 \mathrm{cmH}_{2} \mathrm{O}$ and a respiratory rate (RR) titrated to maintain an end-tidal partial pressure of carbon dioxide $\left(\mathrm{PetCO}_{2}\right)$ between 35 and $45 \mathrm{mmHg}$. Inspiratory pressures were measured with a manometer built into the ventilator. During the entire anesthetic procedure, all dogs received an infusion of a balanced electrolyte solution (Normosol-R; Hospira, Lake Forest, IL, USA) at an approximate rate of $10 \mathrm{ml} \mathrm{kg} \mathrm{kg}^{-1}$ delivered by gravity. A continuous lead II ECG, heart rate (HR), systolic blood pressures 
(SAP) determined at the level of the radial artery by use of noninvasive oscillometric technology with a 3-minute cycling time, hemoglobin oxygen saturation $\left(\mathrm{SpO}_{2}\right)$ measured with a pulse oximeter with the infrared probe placed onto the tongue and $\mathrm{PetCO}_{2}$ using a side stream probe and infrared technology, were continuously monitored throughout anesthesia with an MRI compatible monitor (Medrad Veris MR patient monitor, Warrendale PA, USA) and recorded every 5 minutes.

In order to improve the quality of the MRI images, a 2 minutes-long apnea was required. A bolus of cisatracurium $\left(0.1 \mathrm{mg} \mathrm{kg}^{-1}\right.$; Nimbex, GlaxoSmithKline Pharma, Research Triangle Park, NC, USA) was administered via the fentanyl infusion line to facilitate apnea that was induced 10 minutes later by switching off the ventilator right before starting the cardiac sequences. To avoid inadvertent administration of fentanyl or delay in the infusion, the cisatracurium was injected as a rapid bolus directly into the intravenous catheter through the injection port of the extension line placed between the catheter and the infusion line. Mechanical ventilation was immediately restored if $\mathrm{SpO}_{2}$ showed values below $95 \%$ and in all cases at end of the cardiac MRI sequence. At the end of the MRI study, the anesthetic agents were discontinued and animals were let to breathe spontaneously. The endotracheal tube was removed when the dogs regained the swallowing reflex. The total anesthesia time from anesthesia induction until removal of the endotracheal tube was also measured and recorded (TimeAnesth).

\section{Control group}

In order to create a control group to compare with the GRMDs the anesthesia records of all client owned golden retriever dogs which presented to the Surgery Veterinary Section of the Univeristy of Bari, Italy for elective cataract surgery between January 2007 and Dicember 2010 were retrospectively reviewed. After an initial screening process, the records of 10 male 
Golden retriever dogs aged between 5 and 8.2 years old, with a body weight between 16.3 and $25.2 \mathrm{~kg}$ and with no clinical signs of being affected with X-linked muscular dystrophy were identified and included in the control group. General anesthesia was induced with IV administration of fentanyl $\left(0.010-0.012 \mathrm{mg} \mathrm{kg}^{-1}\right.$; Fentanest; Pharmacia \& Upjohn, Italy) and propofol (1 - $2 \mathrm{mg} \mathrm{kg}^{-1}$ PropVet 1\%; Esteve Hospira Inc, IL, USA) and the dog's trachea was intubated with a cuffed silicone tube. Anesthesia was maintained with a CRI infusion of fentanyl $\left(0.5-0.7 \mu \mathrm{g} \mathrm{kg}^{-1}\right.$ minute $\left.^{-1}\right)$ and the inhalation of isoflurane (Isoba; Shering-Plaugh Spa, Italy). Isoflurane was delivered via a circle system using a small animal anesthesia machine, a precision vaporizer set between $1.5-2 \%$ and oxygen $\left(0.5-1 \mathrm{~L} \mathrm{minute}^{-1}\right)$ as the carrier gas. The lungs of the dogs were ventilated using an electronic mechanical ventilator (Aliseo; Datex Ohmeda, FInland) set in volume controlled mode $\left(12 \mathrm{ml} \mathrm{kg}^{-1}\right)$ and with respiratory rate $(\mathrm{RR})$ titrated to maintain normocapnia $\left(\mathrm{PetCO}_{2}\right.$ between 35 and $45 \mathrm{mmHg}$. All dogs included in this group received an infusion of a ringer lactate solution throughout anesthesia $\left(5-10 \mathrm{~mL} \mathrm{~kg}^{-1} \mathrm{~h}^{-1}\right)$. In addition, dogs received the IV administration of cisatracurium (0.1 $\mathrm{mg} \mathrm{kg}^{-1}$; Nimbex 2; Glaxo Spa, Verona, Italy) 10 minutes before the beginning of the surgery to induce central positioning of the eye and facilitate the surgical conditions. Likewise dogs in DMD group, cardiovascular and respiratory parameters were monitored throughout anesthesia using a multiparameter anesthesia monitor (SC 6002XL; Siemens, MA, USA) and recorded every 5 minutes.

\section{Data analysis and exclusion criteria}

The records of anesthetic episodes of either group were excluded from further analysis if cardiovascularly active drugs such as atropine, dopamine, dobutamine or phenylephrine were administered. In order to analyze the changes induced by the administration of cisatracurium on the HR and SAP, the values collected $15(-15), 10(-10)$ and $5(-5)$ minutes before and 5 
(5), 10 (10), 15 (15), 20 (20), 25 (25) and 30 (30) minutes after the administration of cisatracurium (TimeCIS) were considered for the statistical analysis. The absolute increase or decrease in $\mathrm{HR}(\Delta \mathrm{HR})$ and $\mathrm{SAP}(\triangle \mathrm{SAP})$ within 30 minutes after cisatracurium administration was calculated compared to the values at TimeCIS. In order to normalize the data among the different anesthetic episodes $\Delta \mathrm{HR}$ and $\Delta \mathrm{SAP}$ were computed as percentage of their absolute values at TimeCIS ( $\triangle \mathrm{HR} \%$ and $\triangle \mathrm{SAP} \%$, respectively). The time (minutes) in which the maximum change in HR and SAP occurred was reported for every anesthetic episode as TimeHR and TimeSAP, respectively.

\section{Statistical analysis}

All data were evaluated with descriptive statistics and normal distribution was assessed using the Kolmogorov-Smirnow test. A one-way analysis of variance (ANOVA) for repeated measures followed by a Bonferroni test was used for comparisons of HR and SAP among the study times and between each anesthetic episode of the DMD group. A one-way ANOVA was used to compare the parameters between the control and the DMD group. Nonparametric individual variables were compared among each DMD dog using Friedman's tests followed by Dunnett tests.

\section{Results}

\section{DMD group}

All dogs recovered successfully from each anesthetic episode. No dog showed $\mathrm{SpO}_{2}$ values < 95\% during the entire anesthetic episode including the 2-minutes long apnea. Of all anesthesia records $(n=30), 7$ (one from each dog and another two from dogs 4 and 5) were excluded from statistical analysis. Reasons for exclusion of these records included the 
administration of atropine sulfate $(n=5)$ and/or dopamine $(n=4)$ during anesthesia to treat bradycardia and/or hypotension that occurred before TimeCIS.

Observed differences for $\Delta \mathrm{HR} \%(\%), \Delta \mathrm{HR}$ (beats minute $\left.{ }^{-1}\right), \Delta \mathrm{SAP} \%(\%), \Delta \mathrm{SAP}(\mathrm{mmHg})$, Time HR (min), Time SAP (min) were not statistically significant among dogs.

All anesthesia records that met the inclusion criteria showed increases in HR and SAP after the administration of cisatracurium. The HR was significantly higher compared to TimeCIS at $5,10,15,20,25$ and 30 minutes while SAP was significantly higher only at 5 and 10 minutes after TimeCIS (Figures 1 and 2). The average TimeHR and TimeSAP were $10.2 \pm$ $5.3 \mathrm{~min}$ and $8.0 \pm 2.9 \mathrm{~min}$ respectively. At these time points, the mean $\Delta \mathrm{HR}$ was $78.3 \pm 37.0$ beats/min, which represented a $\Delta \mathrm{HR} \%$ of $115.4 \pm 64.9 \%$ and the mean $\Delta \mathrm{SAP}$ was $33.0 \pm 28.3$ $\mathrm{mmHg}$, which represented a $\triangle \mathrm{SAP} \%$ of $33.5 \pm 31.2 \%$. Values for $\mathrm{PetCO}_{2}$ were statistically significantly different from baseline values only at min 15 (Figure 3). Mean anesthesia time was $219.5 \pm 16.3 \mathrm{~min}$. No other evaluated physiologic parameter showed statistically significant differences compare with baseline after TimeCIS. All other analyzed parameters in DMD group did not show statistically significant differences among anesthetic episodes.

\section{Control group}

All dogs recovery successfully form anesthesia. All anesthesia records met the inclusion criteria. Mean $\pm \mathrm{SD}$ values of $\mathrm{HR}, \mathrm{SAP}$ and $\mathrm{PetCO} 2$ for each evaluated time point are reported in figures 1, 2 and 3. Mean values for HR, SAP and PetCO2 were comparable between each studied time point. The mean $\Delta \mathrm{HR}$ was $1.2 \pm 0.3$ beats minute ${ }^{-1}$ corresponding to a $\Delta \mathrm{HR} \%$ of $1.4 \pm 0.5 \%$ that occurred at a mean TimeHR of $5.2 \pm 0.9$ minutes. The mean value of $\Delta \mathrm{SAP}$ was $1.5 \pm 0.4 \mathrm{mmHg}$ corresponding to a $\triangle \mathrm{SAP} \%$ of $1.5 \pm 0.2 \%$ that occurred at a mean TimeSAP of $10.3 \pm 1.2$ minutes. All the other evaluated physiological parameters did not show statistically significant difference after TimeCIS. 


\section{Discussion}

Intra-anesthetic increases in $\mathrm{HR}$ and SAP occur as a response to the activation of the autonomic system and could be induced by several determinants such as nociception, changes in anesthetic depth, hypovolemia, hypercarbia, hypoxemia and administration of anticholinergic and/or adrenergic agents among many others. Nevertheless, in these GRMD dogs, most of these factors were ruled out as potential contributors for the observed effects because dogs were not moved and remained in the same position during the entire procedure, in a closed MRI, at a fairly constant propofol/fentanyl infusion and crystalloid rates, showing values of $\mathrm{SpO}_{2}>95 \%$, without the administration of vasoactive agents or nociceptive stimuli and having always the same anesthetist performing all anesthesias. Although hypercarbia can cause both, increases in HR and SAP, in the present report the apnea-related increases in $\mathrm{PetCO}_{2}$ probably occurred when discontinuing the ventilator 10 min after the administration of Cisatracurium, as seen in the significantly increased $\mathrm{PetCO}_{2}$ values observed at 15 min. Therefore, it is possible that in the present report these changes in HR and SAP are related with the IV administration of clinically used doses of Cisatracurium. The mild hypercarbia recorded after the apneustic episode may have contributed with the highest values observed for HR and SAP at that point and also with the duration of the increases in HR. Interestingly, cisatracurium, like gallamine, pancuronium and atropine, behaved in vitro as a type 2 atrial muscarinic receptor (M2) antagonist (9). However, the results of the present study suggest that cisatracurium administration to anesthetized golden retriever dogs with no 
signs of being affected with X-linked muscular dystrophy does not affect HR and SAP in the same manner as when equivalent doses are administered to GRMDs. Despite that anesthesia was maintained with different general anesthetics (i.e. propofol vs isoflurane) it is unlikely that the administration of isoflurane to the control group would blunt potential cisatracuriuminduce vagolytic responses in this group.. Reports of patients anesthetized with volatile agents or propofol infusions receiving cisatracurium do not associate cardiovascular changes with the administration of this $\operatorname{NDNMB}(10,11)$. In addition, the results of this study are in agreement with previous reports in which cisatracurium was administered to healthy mongrel dogs or dogs of different breeds affected with portosystemic shunt and did affect HR or blood pressure values $(9,12)$. Similarly, only minor cardiovascular changes were observed in surgical patients not affected with DMD that received 2-5 x ED $\mathrm{ED}_{95}$ of Cisatracurium (13). In another study in which the cardiovascular effects of Cisatracurium were evaluated in hemodynamically stable patients undergoing cardiovascular bypass, the administration of this NDNMB at a bolus dose of 6-8 x ED95 only caused small decrease in HR and no changes in mean arterial pressure (14).

Another possible factor to consider is the role which gene therapy might have played in the increased autonomic responses observed in the DMD group after cisatracurium administration. The gene treatment was directly injected into the myocardium of these dogs and could have potentially influenced their cardiac autonomic function. However, this hypothesis is improbable considering that the transgene which was used in these GRMDs is not expressed in the nervous system (8). Moreover, the first anesthetic episode was performed before the myocardial injection of the gene vector and the fact that the increases in HR and SAP were comparable among anesthetic episodes, including that very first one, supports the theory that gene therapy was not the reason for the augmented autonomic response observed after cisatracurium administration in the DMD group. 
It is recognized that the autonomic system function is affected in patients with Duchenne muscular dystrophy and that the severity of the disease significantly correlates with the impairment of the autonomic function (i.e. significant decrease in parasympathetic activity and a significant increase in sympathetic activity with severe disease) (15). This situation characterizes a variety of arrhythmias typical of both, the early and late phase of the disease (16). Although up-regulation of nicotinic receptors with low affinity for some NDNMBs and prolonged paralysis after administration of NDNMBs have been reported in patients affected with DMD (17) little is known about the autonomic system activity and drug(s) interacting with nicotinic and/or muscarinic receptors in these patients. Therefore, in the present report, it can only be hypothesized that a pre-existing imbalance of the autonomic system and/or an amplified antagonistic effect of Cisatracurium on M2 atrial receptors augmented the sympathetic tone in these GRMD dogs resulting in significantly increased HR and SAP values. Although these increases (115\% for HR and 33\% for SAP) may be well tolerated in patients with normal myocardial function, they potentially could precipitate acute cardiac failure in patients with severe cardiomyopathies, which are present in $90 \%$ of patients affected with DMD (18).

To the authors' knowledge, this is the first report describing significant autonomic responses potentially associated with the administration of cisatracurium in anesthetized subjects affected with X-linked muscular dystrophy. An anecdotal report, described the use of atracurium to facilitate endotracheal intubation in a 12-year boy affected with DMD (7). The absence of vagolysis with atracurium combined with the ability to allow reversal to occur without using neostigmine and atropine was recognized as a significant advantage and atracurium was regarded as the most suitable NDNMB to use in patients with DMD. However, it is suspected that Cis-isomer of atracurium, Cisatracurim, caused the observed increases in HR and SAP in these GRMDs. Therefore, until research and clinical trials 
demonstrate its safety, the use of Cisatracurium in DMD patients should be considered with caution.

\section{REFERENCES}

1. Monaco AP, Neve RL, Colletti-Feener C, et al. Isolation of candidate cDNAs for portions of the Duchenne muscular dystrophy gene. Nature 1986; 323: 646 - 50.

2. Strober JB. Therapeutics in Duchenne muscular dystrophy. NeuroRx 2006; 3: 225 34.

3. Willmann R, Possekel S, Dubach-Powell J, et al. Mammalian animal models for Duchenne muscular dustrophy. Neuromuscul Disord 2009; 19: 241 - 9.

4. Valentine BA, Cooper BJ, deLahunta A, et al. Canine X-linked muscular dystrophy. An animal model of Duchenne muscular dystrophy: clinical studies. J Neurol Sci 1988; 88: $69-81$.

5. Birnkrant DJ, Panitch HB, Benditt JO, et al. American College of Chest Physicians consensus statement on the respiratory and related management of patients with Duchenne muscular dustrophy undergoing anesthesia or sedation. Chest 2007; 132 : $1977-86$.

6. Gurnaney H, Brown A, Litman RS. Malignant hyperthermia and muscular dystrophies. Anesth Analg 2009; 109: 1043 - 8 .

7. Rosewarne FA. Anaesthesia, atracurium and Duchenne muscular dystrophy. Can Anaesth Soc J 1986; 33: 250 - 1. 
8. Bish LT, Sleeper MM, Brainard B, et al. Percutaneous transendocardial delivery of self-complementary adeno-associated virus 6 achieves global cardiac gene transfer in canines. Mol Ther 2008; 16: 1953 - 9.

9. Patterson E, Scheriag BJ, Zhou J, et al. Antifibrillatory actions of cisatracurium: an atrial specific M2 receptor antagonist. J Cardiovasc Electrophysiol 2008; 19: 861 - 8.

10. Grundmann U, Uth M, Eichner A, et al. Total Intravenous anaesthesia with propofol and remifentanil in paediatric patients: a comparison with a desflurane-nitrous oxide inhalation anaesthesia. Acta Anaestesiol Scand 1998; 42: 845 - 850.

11. Modesti C, Sacco T, Morelli G, et al. Balanced anesthesia versus total intravenous anesthesia for kidney transplantation. Minerva Anestesiol 2006; 72: 7 - 8 .

12. Adams WA, Senior MJ, Jones RS, et al. cis-Atracurium in dogs with and without porto-systemic shunts. Vet Anaesth Analg 2006; 33: 17 - 23.

13. Soukup J, Doenicke A, Hoernecke R, et al. Cardiovascular effects after a bolus administration of cisatracurium. A comparison with vecuronium. Anaesthesist 1996; 45: $1024-9$.

14. Reich DL, Mulier J, Viby-Mogensen J, et al. Comparison of the cardiovascular effects of cisatracurium and vecuronium in patients with coronary artery disease. Can J Anaesth 1998; 45: $794-7$.

15. Inoue M, Mori K, Hayabuchi Y, et al. Autonomic function in patients with Duchenne muscular dystrophy. Pediatr Int 2009; 51: $33-40$.

16. Finsterer J, Stollberger C. The heart in human dystrophinopathies. Cardiology 2003; 99: $1-19$.

17. Driessen J, Snoeck M. Duchenne muscular dystrophy: which is the best anesthetic agent? Paediatr Anaesth 2008; 18: 1007 - 8. 
18. Fassoil A, Nardi O, Orlikowski D, et al. Cardiomyopathy in Duchenne muscular dystrophy: pathogenesis and therapeutics. Heart Fail Rev 2010; 15: $103-7$. 
Figure 1.

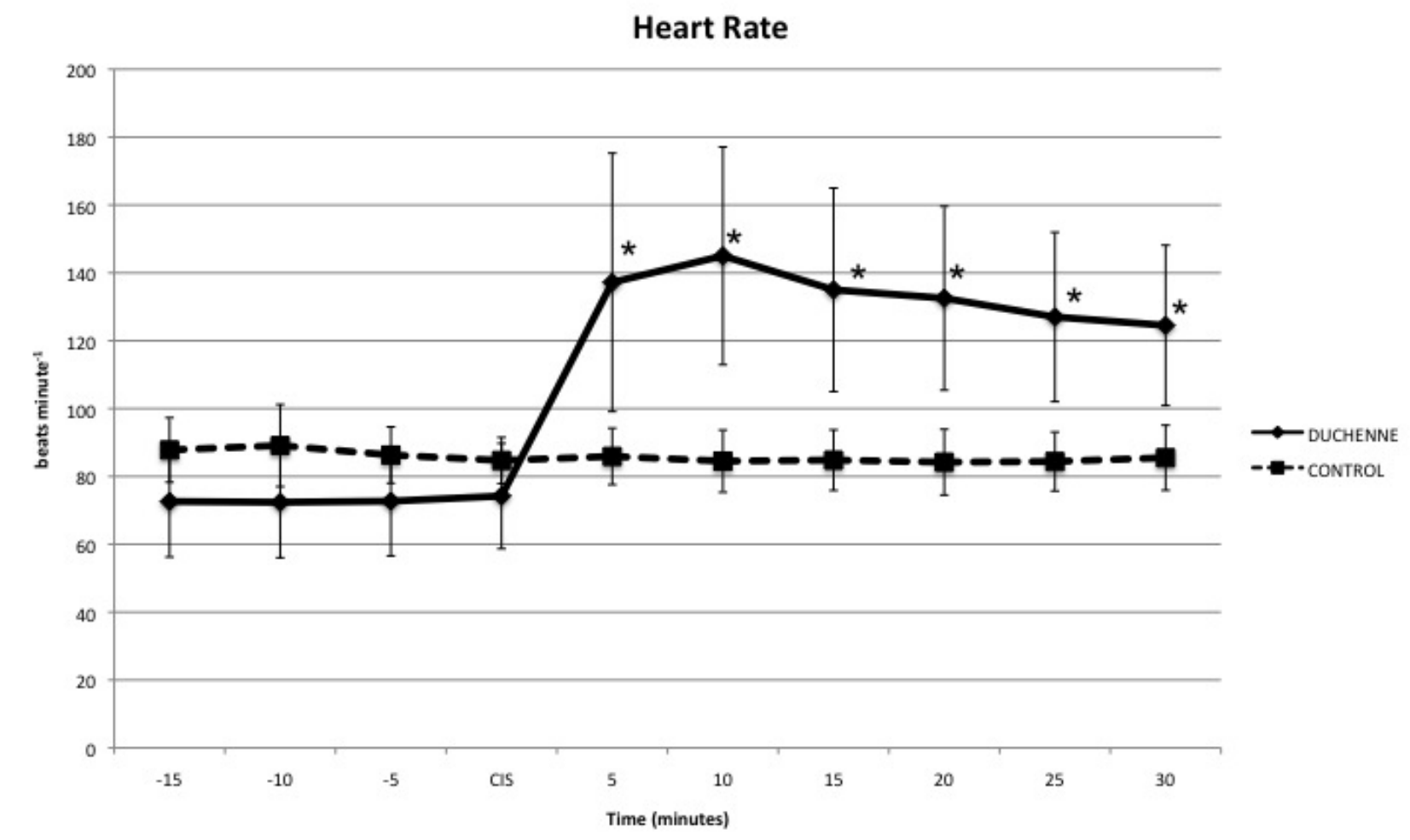

Figure 2.

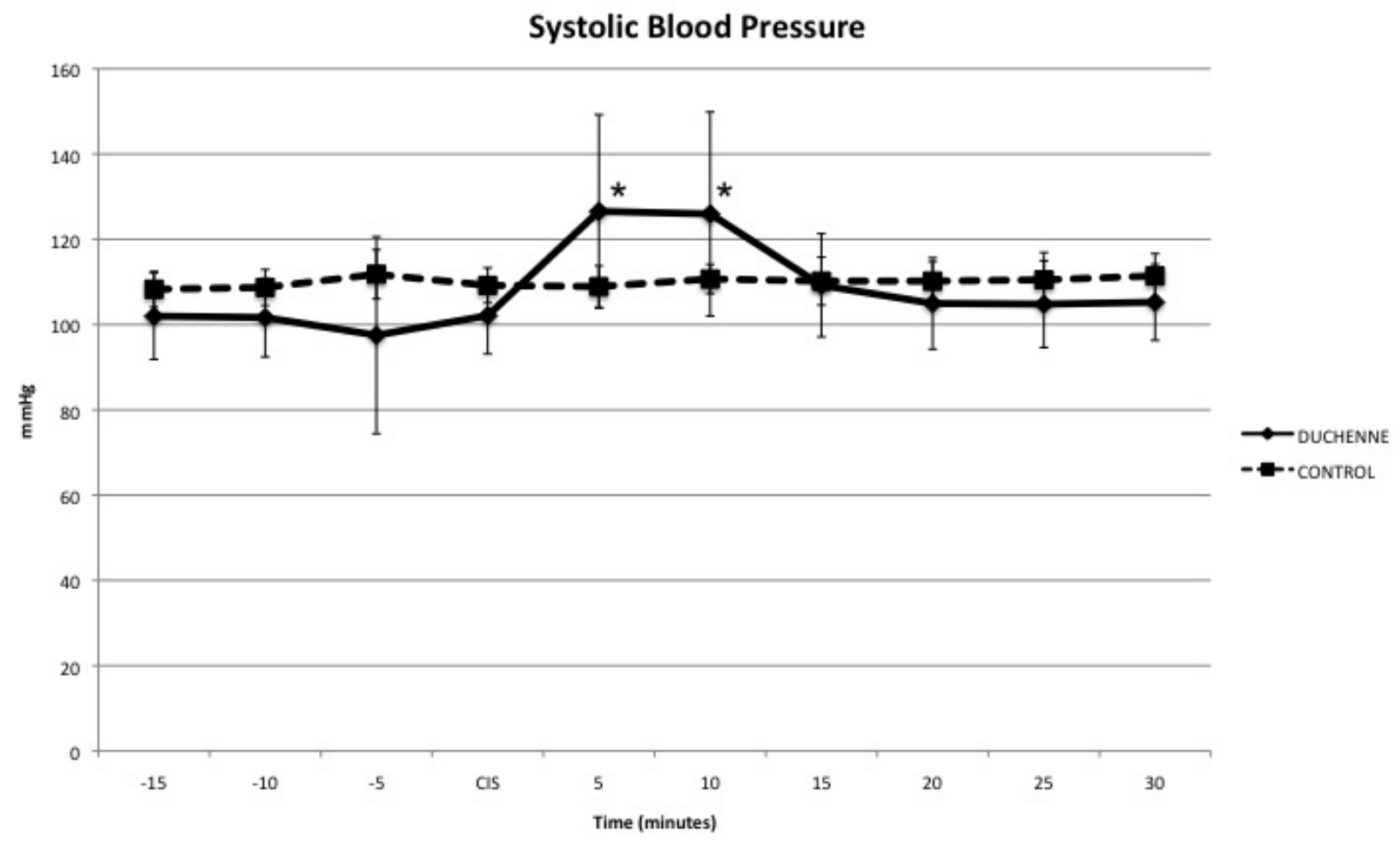


Figure 3.

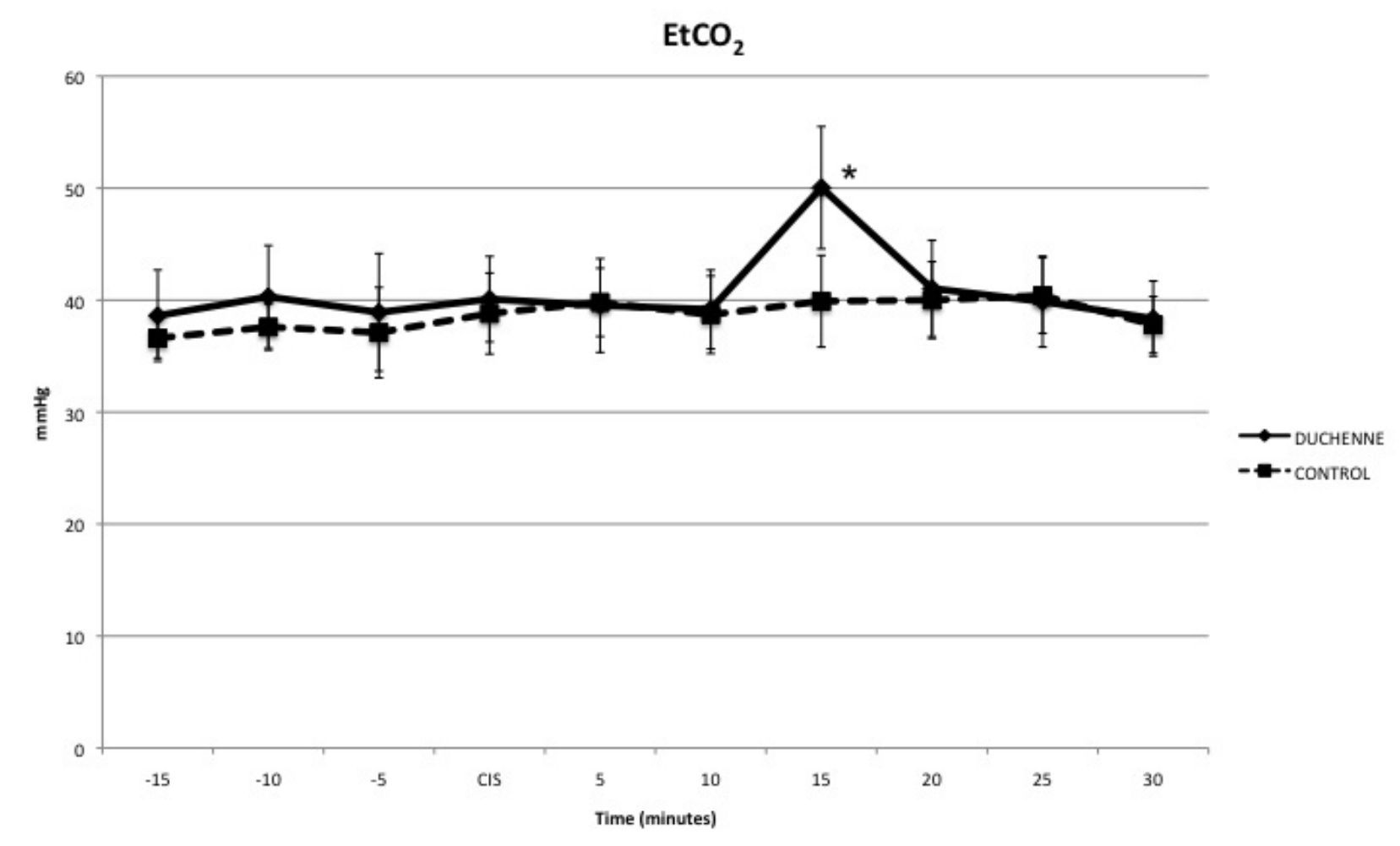


Figure 1. Mean heart rate and the respective SDs (bars) obtained from anesthetized dogs affected (continuous line) and not affected (interrupted line) with X-linked muscular dystrophy, which received cisatracurium (CIS). * Statistically significantly different compared to the value at CIS within the same group $(\mathrm{P}<0.05$ ANOVA)

Figure 2. Mean systolic blood pressure and the respective SDs (bars) obtained from anesthetized dogs affected (continuous line) and not affected (interrupted line) with X-linked muscular dystrophy, which received cisatracurium (CIS). * Statistically significantly different compared to the value at CIS within the same group $(\mathrm{P}<0.05$ ANOVA)

Figure 3. Mean end-tidal partial pressure of carbon dioxide $\left(\mathrm{EtCO}_{2}\right)$ and the respective SDs (bars) obtained from anesthetized dogs affected (continuous line) and not affected (interrupted line) with Xlinked muscular dystrophy, which received cisatracurium (CIS). * Statistically significantly different compared to the value at CIS within the same group $(\mathrm{P}<0.05$ ANOVA $)$ 
Mean heart rate and the respective SDs (bars) obtained from anesthetized dogs affected (continuous line) and not affected (interrupted line) with X-linked muscular dystrophy, which received cisatracurium (CIS). * Statistically significantly different compared to the value at CIS within the same group $(P<0.05$ ANOVA) $256 \times 156 \mathrm{~mm}(72 \times 72 \mathrm{DPI})$ 


\begin{abstract}
Mean systolic blood pressure and the respective SDs (bars) obtained from anesthetized dogs affected (continuous line) and not affected (interrupted line) with X-linked muscular dystrophy, which received cisatracurium (CIS). * Statistically significantly different compared to the value at CIS within the same group $(P<0.05$ ANOVA) $256 \times 156 \mathrm{~mm}$ (72 x 72 DPI)
\end{abstract}




\begin{abstract}
Mean end-tidal partial pressure of carbon dioxide (EtCO2) and the respective SDs (bars) obtained from anesthetized dogs affected (continuous line) and not affected (interrupted line) with X-linked muscular dystrophy, which received cisatracurium (CIS). * Statistically significantly different compared to the value at CIS within the same group $(P<0.05$ ANOVA)
\end{abstract} $256 \times 156 \mathrm{~mm}(72 \times 72 \mathrm{DPI})$ 